\title{
Acute pancreatitis after argon plasma coagulation of duodenal polyps in a patient with familial adenomatous polyposis
}

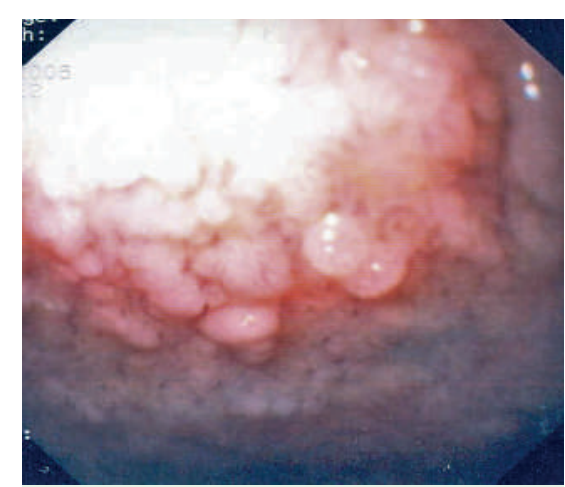

Fig. 1 This endoscopic image shows typical large flat adenomatous polyps in the superior duodenal flexure. These were found in considerable numbers in our patient.

Duodenal adenomas occur almost invariably in familial adenomatous polyposis [1], and patients with this syndrome can develop duodenal and ampullary cancers [2]. Therapies to prevent malignant transformation of duodenal adenomas include cyclo-oxygenase-2 inhibition, endoscopic mucosal resection, polypectomy, and ablation with argon plasma coagulation (APC) [3].

A 43-year-old woman with familial adenomatous polyposis underwent esophagogastroduodenoscopy for ablation of multiple duodenal adenomatous polyps ( Fig. 1) using intermittent pulses of APC (30 W) (Erbe, Tübingen, Germany). During one ablation a short submucosal gas injection occurred and this was perceived by the patient as a brief episode of pain that resolved spontaneously. Six hours after the procedure the patient developed epigastric pain and a slightly tense upper abdomen. Computed tomography performed approximately 12 hours after the procedure revealed edematous

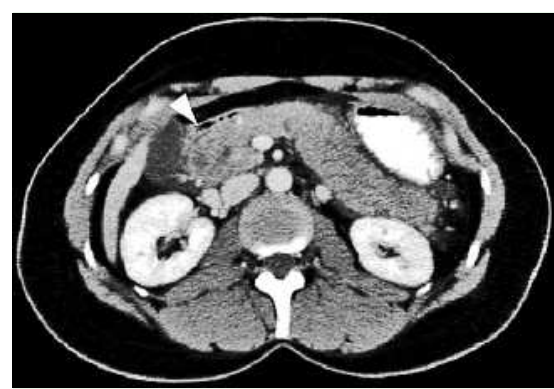

Fig. 2 A contrast-enhanced computed tomographic image showing edema of the pancreas and a small fluid collection around the pancreatic head (arrowhead).

swelling of the pancreas and a small fluid collection around the pancreatic head ( Fig. 2). Laboratory tests revealed elevated levels of pancreatic amylase (33.3 $\mu \mathrm{mol} / \mathrm{L}$ [normal range $<0.88 \mu \mathrm{mol} /$ L]) and lipase $(30.2 \mu \mathrm{mol} / \mathrm{L}$ [normal range $<1.0 \mu \mathrm{mol} / \mathrm{L}])$, and a leukocyte count of $16.6 \times 10^{9} / \mathrm{L}$. A diagnosis of mild acute interstitial pancreatitis was made. The patient recovered within 3 days after the onset of pain.

This case report highlights a previously unrecognized potential complication of APC. We have considered three potential explanations for the development of pancreatitis in our patient. Firstly, the accidental submucosal gas injection could have penetrated into the pancreas and caused inflammation. Secondly, the papilla could have been traumatized by the APC, although no ablation was performed near the papilla during this particular endoscopic procedure. Thirdly, a high volume of gas in the duodenum could have increased the pressure in the pancreaticobiliary tree [4]. Although APC only penetrates the mucosa to a limited degree, it has been associated with complications such as hollow viscus perforation and abscess formation. To our knowledge there have been no previous reports of pancreatitis associated with APC.

Endoscopy_UCTN_Code_CPL_1AH_2AZ Endoscopy_UCTN_Code_CPL_1AH_2AK

\section{J. Weigt, L. C. Zimmermann,}

\section{K. Mönkemüller, P. Malfertheiner}

Department of Gastroenterology, Hepatology and Infectious Diseases, Otto von Guericke University Magdeburg, Magdeburg, Germany

\section{References}

1 Heiskanen I, Kellokumpu I, Jarvinen H. Management of duodenal adenomas in 98 patients with familial adenomatous polyposis. Endoscopy 1999; 31: 412-416

2 Bülow S, Björk J, Christensen IJ et al, and the DAF Study Group.. Duodenal adenomatosis in familial adenomatous polyposis. Gut 2004; 53: 381 - 386

3 Kashiwagi H, Spigelman AD. Gastroduodenal lesions in familial adenomatous polyposis. Surg Today 2000; 30: 675-682

4 Groenen MJ, Moreels TG, Orlent $\mathrm{H}$ et al. Acute pancreatitis after double-balloon enteroscopy: an old pathogenetic theory revisited as a result of using a new endoscopic tool. Endoscopy 2006; 38: $82-85$

Bibliography

DOI 10.1055/s-2007-966664

Endoscopy 2007; 39: E278

(c) Georg Thieme Verlag KG Stuttgart · New York . ISSN 0013-726X

\section{Corresponding author \\ K. Mönkemüller, MD}

Department of Gastroenterology,

Hepatology and Infectious Diseases

Otto-v.-Guericke University Magdeburg

Leipziger Str. 44

39120 Magdeburg

Germany

Fax: +49-3916713105

klaus.moenkemueller@medizin.

uni-magdeburg.de 